\title{
Natural Plant-Based Additives Can Improve Ruminant Performance by Influencing the Rumen Microbiome
}

Mariana Ornaghi ( $\sim$ marianaornaghi@hotmail.com )

Universidade Estadual de Maringa https://orcid.org/0000-0003-1440-5861

Rodolpho M. Prado

Universidade Estadual de Maringa

Tatiane R. Ramos

Universidade Estadual de Maringa

Francisco R. Catalano

Faculdade Integrado de Campo Mourao

Camila Mottin

Faculdade Integrado de Campo Mourao

Christopher J. Creevey

Queen's University Belfast

Sharon A. Huws

Queen's University Belfast

Ivanor N. Prado

Universidade Estadual de Maringa

\section{Research Article}

Keywords: essential oils, feedlot, microbiome, microbiota, rumen

Posted Date: May 21st, 2020

DOI: https://doi.org/10.21203/rs.3.rs-29748/v1

License: (c) (i) This work is licensed under a Creative Commons Attribution 4.0 International License. Read Full License 


\section{Abstract}

Background The use of synthetic compounds as growth promoters in animal production, is now limited or even banned by health agencies globally due to human safety concerns. In feedlot cattle, when using high grain diets, it is necessary to supplement the diet with compounds capable of modulating the rumen in order to reduce the incidence of acidosis and improve growth. In this context, natural substances have become promising substitutes. The objective of this study was to evaluate the effects of a natural additive blend (NA) on animal performance, the rumen microbiome and ingestive behavior in 40 young bulls.

Results The initial and final average body weight was similar $(P>0.05)$ for all diets, although average daily gain increased linearly $(P<0.01)$ when NA was fed. However, feed efficiency improved linearly $(P<0.05)$ by including NA in the diet. Principal volatile fatty acid: acetic, butyric, isovaleric and valeric decreased linearly $(P<0.02)$ following NA addition. Similarly, NA addition linearly decreased $(P<0.02)$ the acetate/propionate ratio. The propionate and isobutyric acid concentrations showed a positive quadratic effect $(P<0.05)$. Furthermore, NA addition reduced ammonia concentrations $(P<0.001)$ and ruminal $\mathrm{pH}$ was not affected $(P>0.05)$ by the diets. The rumen microbiome was significantly different between beef cattle fed the different treatments $(\mathrm{P}<0.05)$, with a reduction in the archaea, and within the Clostridium, Robinsoniella, Acidaminococcus, Acetitomaculum, Succinimonas and Weissella $(P<0.05)$ seen when NA was fed. The functional capacity of the rumen microbiome was affected following NA supplementation. Overall, we observed Aldehyde oxidase/xanthine dehydrogenase, molybdopterin binding; RecG, N-terminal antiparallel four helix bundle; Transposase, ISC1217; Restriction endonuclease, type II, Xaml; Acyl-protein synthetase, LuxE; ABC-2 transporter; which could be related to the natural additives mechanism of action.

Conclusions Animal performance was improved in a dose-dependent manner by natural additive addition to the diet of bulls. These beneficial effects are correlated to changes in the rumen microbiome. Our findings suggest that the natural additive blend used in this study could be used as an alternative natural substitute to synthetic antibiotics for animal production.

\section{Background}

Ruminants obtain their energy for maintenance and production largely through the feed and the fermentative capacity of the rumen microbiome, resulting in the production of short-chain fatty acids, especially acetate, propionate and butyrate. However, the fermentation process also produces secondary gases, like methane, which can represent losses of up to $12 \%$ of the total energy intake, thus affecting feed efficiency [1, 2]. Additionally, the accumulation of short-chain fatty acids in the rumen for long periods can result in ruminal abnormal function, and additives are often used to prevent this occurrence. Of those, antibiotics are additives largely used to prevent metabolic disorders and to improve animal efficiency in many non-EU countries [3]. However, there is increasing public concern regarding antibiotic resistance [3]. Thus, some countries are limiting (FDA, 2015) or even banning (EU; OJEU, 2003) the use of antibiotics in animal feed as precautionary measures against antimicrobial resistance. This is pivotal given that there is evidence that the rumen is likely a reservoir of antibiotic resistance genes [4].

There is potential to use natural products as substitutes to antibiotics in ruminant nutrition, such as natural additives (NA) from plant extracts, and essential and functional oils $[5,6,7,8,9]$. Essential and functional oils have active secondary metabolites produced by plants. These secondary metabolites are reported as having antibacterial, antifungal and antioxidant activity $[10,11]$. Secondary metabolites having antimicrobial effects can act by inhibiting RNA, DNA and protein synthesis, and even damaging cell membrane [12]. Therefore, these metabolites may manipulate rumen fermentation resulting in improved feed efficiency. Furthermore, there is evidence that the volatile and odorant compounds in secondary metabolites improve palatability of the diet [13]. 
Active compounds in plants are dependent on biotic (i.e. species, portion, etc.) and abiotic (i.e. temperature, humidity, etc.) factors. Clove oil (Syzygium aromaticum) is enriched in eugenol, which was reported as having antimicrobial properties [14]. Vanilla (Vanilla planifolia) and thyme (Thymus vulgaris) are enriched in vanillin and thymol, respectively, which were reported as having antimicrobial [15] and antioxidant activity [16]. Cashew nut oil (Anacardium occidentale) and castor oil (Ricinus communis), which are enriched in cardanol, cardol and anacardic acid, were also reported as having antimicrobial properties [17]. These active compounds have potential to affect Gram-positive and Gram-negative bacteria [18] and synergetic effects of using plants extracts have been reported [19].

The authors have recently reported improved performance of beef cattle supplemented with either 3.5 or $7.0 \mathrm{~g} / \mathrm{day}$ per animal of essential oils from clove or cinnamon [20]. However, mechanistic effects of NA on the rumen microbiome remains poorly explored, but it is assumed that the rumen function is likely different. Thus, in this study we fed beef cattle with increasing levels of NA (essential oil from clove leaf, castor and cashew functional oils, and a commercial blend composed of vanillin, eugenol and thymol) and evaluated animal performance and rumen parameters.

Furthermore, we used shotgun metagenomics to explore underlying changes in the rumen microbiome. In summary, this study provides a comprehensive understanding of the effects of a commercially available natural plant-based additive blend on ruminant performance alongside a comprehensive understanding of the mechanism of action within the rumen.

\section{Results}

\section{Animals diet}

Bulls were fed a basal diet comprised of $70 \%$ concentrate containing corn grain offered ad libitum and protein supplement (soybean meal; premix composed of: urea, vitamins and minerals; limestone; yeast and salt) and $30 \%$ corn silage for 62 days (Table 1 ). 
Table 1

Ingredients and chemical composition of basal diet ( $\mathrm{g} / \mathrm{kg} \mathrm{DM})$

\begin{tabular}{|c|c|}
\hline Ingredients & Diet \\
\hline Corn silage & 275.9 \\
\hline Corn grain & 613.2 \\
\hline Soybean meal & 51.0 \\
\hline Premix $^{1}$ & 50.5 \\
\hline Mineral salt & 4.5 \\
\hline Limestone & 4.5 \\
\hline Yeast & 0.4 \\
\hline \multicolumn{2}{|l|}{ Chemical composition } \\
\hline Dry matter & 577 \\
\hline Crude protein & 132 \\
\hline Organic matter & 968 \\
\hline Ash & 31.4 \\
\hline Ether extract & 40.1 \\
\hline Neutral detergent fibre & 288 \\
\hline Acid detergent fibre & 117 \\
\hline Total digestible nutrients & 790 \\
\hline Metabolisable energy (MJ/kg DM) & 11.9 \\
\hline Calcium & 6.82 \\
\hline Phosphorus & 3.56 \\
\hline \multicolumn{2}{|c|}{$\begin{array}{l}{ }^{1} \text { Premix: magnesium }(57 \mathrm{~g} / \mathrm{kg}) \text {, sodium }(81 \mathrm{~g} / \mathrm{kg}) \text {, sulphur }(3.75 \mathrm{~g} / \mathrm{kg}) \text {, cobalt }(20 \mathrm{mg} / \mathrm{kg}) \text {, copper }(500 \mathrm{mg} / \mathrm{kg}) \text {, iodine } \\
(25 \mathrm{mg} / \mathrm{kg}) \text {, manganese }(1500 \mathrm{mg} / \mathrm{kg}) \text {, selenium }(10 \mathrm{mg} / \mathrm{kg}) \text {, zinc }(2000 \mathrm{mg} / \mathrm{kg}) \text {, vitamin A }(400000 \mathrm{Ul} / \mathrm{kg}) \text {, vitamin } \\
\text { D3 (50 000 Ul } / \mathrm{kg}) \text {, vitamin E }(750 \mathrm{Ul} / \mathrm{kg}) \text {, ether extract }(168 \mathrm{~g} / \mathrm{kg}) \text { and urea }(200 \mathrm{~g} / \mathrm{kg}) \text {. }\end{array}$} \\
\hline
\end{tabular}

\section{Feeding behavior activities}

There were no effects of NA blend addition to bull diets on rumination, feed intake, water intake and idle time $(P>0.05$; Table 2). 


\begin{tabular}{|c|c|c|c|c|c|c|c|}
\hline \multirow[b]{2}{*}{ Activities, min/day } & \multicolumn{5}{|c|}{ Experimental diets } & \multirow{2}{*}{ SEM $^{6}$} & \multirow[t]{2}{*}{$P$ - value } \\
\hline & $\mathrm{CON}^{1}$ & NA1 $15^{2}$ & NA30 ${ }^{3}$ & NA45 ${ }^{4}$ & NA60 5 & & \\
\hline Rumination & 245.0 & 219.5 & 209.5 & 262.0 & 245.0 & 9.911 & 0.550 \\
\hline Feed intake & 343.5 & 349.5 & 344.5 & 305.5 & 337.5 & 9.182 & 0.394 \\
\hline Water Ingestion & 35.0 & 34.5 & 38.0 & 32.0 & 37.0 & 2.451 & 0.932 \\
\hline Idle & 816.5 & 836.5 & 848.0 & 840.5 & 820.5 & 11.392 & 0.883 \\
\hline \multicolumn{8}{|c|}{$\begin{array}{l}{ }^{1} \mathrm{CON}=\text { control (without natural additives); }{ }^{2} \mathrm{NA} 15 \text { - addition of } 1.5 \mathrm{~g} / \text { animal/day of natural additives; }{ }^{3} \mathrm{NA} 30- \\
\text { addition of } 3.0 \mathrm{~g} / \mathrm{animal} / \text { day of natural additives; }{ }^{4} \mathrm{NA} 45 \text { - addition of } 4.5 \mathrm{~g} / \text { animal/day of natural additives; }{ }^{5} \mathrm{NA} 60 \\
- \text { addition of } 6.0 \mathrm{~g} / \text { animal/day of natural additives. Naturals additives contained clove leaf essential oil, castor and } \\
\text { cashew functional oils and a commercial blend composed of vanillin, eugenol and thymol; }{ }^{6} \text { Standard error of means; } \\
{ }^{7} \text { Linear effect; }{ }^{8} \text { Quadratic effect. }\end{array}$} \\
\hline
\end{tabular}

Table 2

Feeding behavior from young bulls with and without natural additive addition to the diet

\section{Animal performance}

The initial body weight and final body weight (FBW) were similar for all diets $(P>0.05)$, nonetheless average daily gain (ADG) of bulls increased linearly $(P<0.01)$ when the NA blend was added in the diets (Table 3$)$. The addition of NA in the diets had no effect $(P>0.05)$ on Dry Matter Intake (DMI) $(\mathrm{kg} /$ day -9.9 or kg/100 kg body weight $-2.3 \%)$. However, feed efficiency improved linearly $(P<0.04)$ with the addition of NA to the diets (Table 3$)$. In addition, the HCW (Hot Carcass Weight) and HCD (Hot Carcass Dressing) did not differ between cattle fed with blend of NA $(P>0.05$; Table 3$)$.

\begin{tabular}{|c|c|c|c|c|c|c|c|c|c|}
\hline \multirow[b]{2}{*}{ Item } & \multicolumn{6}{|c|}{ Experimental diets } & \multicolumn{3}{|c|}{$P$ - value } \\
\hline & $\mathrm{CON}^{1}$ & NA15 2 & $\mathrm{NA} 30^{3}$ & NA45 4 & NA60 5 & SEM ${ }^{6}$ & $\mathrm{~L}^{7}$ & $Q^{8}$ & $0 \%$ vs blend \\
\hline Initial body weight, kg & 382.8 & 388.0 & 385.6 & 385.4 & 387.3 & 2.941 & 0.762 & 0.641 & 0.623 \\
\hline Final body weight, kg & 473.0 & 478.7 & 481.4 & 486.9 & 490.0 & 3.942 & 0.131 & 0.322 & 0.267 \\
\hline Average daily gain, kg & 1.43 & 1.44 & 1.52 & 1.61 & 1.63 & 0.031 & 0.013 & 0.047 & 0.145 \\
\hline Dry matter intake, $\mathrm{kg} / \mathrm{d}$ & 9.85 & 9.80 & 9.83 & 10.12 & 10.09 & 0.144 & 0.300 & 0.521 & 0.706 \\
\hline Dry matter intake, \%/BW & 2.30 & 2.26 & 2.27 & 2.32 & 2.33 & 0.024 & 0.542 & 0.670 & 0.909 \\
\hline Feed efficiency, kg & 0.145 & 0.147 & 0.155 & 0.160 & 0.160 & 0.014 & 0.043 & 0.134 & 0.216 \\
\hline Hot carcass weight, kg & 248.1 & 252.0 & 246.6 & 253.9 & 246.1 & 2.521 & 0.900 & 0.879 & 0.816 \\
\hline Hot carcass dressing, $\%$ & 52.37 & 52.62 & 51.25 & 52.18 & 51.51 & 0.302 & 0.178 & 0.195 & 0.357 \\
\hline \multicolumn{10}{|c|}{$\begin{array}{l}{ }^{1} \mathrm{CON}=\text { control (without natural additives); }{ }^{2} \mathrm{NA} 15-\text { addition of } 1.5 \mathrm{~g} / \text { animal/day of natural additives; }{ }^{3} \mathrm{NA} 30- \\
\text { addition of } 3.0 \mathrm{~g} / \mathrm{animal} / \text { day of natural additives; }{ }^{4} \mathrm{NA} 45-\text { addition of } 4.5 \mathrm{~g} / \text { animal/day of natural additives; }{ }^{5} \mathrm{NA} 60 \\
- \text { addition of } 6.0 \mathrm{~g} / \text { animal/day of natural additives. Naturals additives contained clove leaf essential oil, castor and } \\
\text { cashew functional oils and a commercial blend composed of vanillin, eugenol and thymol; }{ }^{6} \text { Standard error of means; } \\
{ }^{7} \text { Linear effect; }{ }^{8} \text { Quadratic effect. }\end{array}$} \\
\hline
\end{tabular}

Table 3 


\section{Ruminal ammonia and volatile fatty acid (VFA).}

The addition of a blend of NA affected rumen fermentative characteristics and resultant VFAs produced (Table 4). The major VFAs: acetate, butyrate, isovalerate, and valerate were reduced linearly when animals were fed NA $(P<0.05)$. Similarly, NA addition in the diets linearly reduced $(P<0.02)$ the acetate/propionate ratio. NA supplementation of diets resulted in a quadratic effect on propionate and isobutyric acid concentrations $(P<0.05)$. Furthermore, animals supplied with NA had linear reductions in rumen methane concentration $(P<0.001)$. Ammonia concentration had a quadratic effect following NA blend supplementation of bull diets $(P<0.001)$. The ruminal $\mathrm{pH}$ was not affected $(P>0.05)$ by inclusion of NA in the diets (Table 4).

\begin{tabular}{|c|c|c|c|c|c|c|c|c|c|}
\hline \multirow[b]{2}{*}{ Item } & \multicolumn{6}{|c|}{ Experimental diets } & \multicolumn{3}{|c|}{$P$ - value } \\
\hline & $\mathrm{CON}^{1}$ & NA15 ${ }^{2}$ & $\mathrm{NA} 30^{3}$ & NA45 ${ }^{4}$ & NA60 5 & SEM $^{6}$ & $\mathrm{~L}^{7}$ & $Q^{8}$ & $\begin{array}{l}0 \% \text { vs } \\
\text { blend }\end{array}$ \\
\hline Acetate $(\mathrm{mmol} / \mathrm{mol})$ & 56.15 & 56.16 & 43.64 & 43.98 & 43.74 & 1.31 & $<.0001$ & $<.0001$ & $<.0001$ \\
\hline $\begin{array}{l}\text { Propionate } \\
\text { (mmol/mol) }\end{array}$ & 17.45 & 17.00 & 14.44 & 16.37 & 13.69 & 0.73 & 0.350 & 0.054 & 0.682 \\
\hline Isobutyric (mmol/mol) & 0.91 & 1.18 & 0.85 & 0.79 & 0.93 & 0.03 & $<.0001$ & 0.038 & 0.623 \\
\hline Butyrate (mmol/mol) & 10.87 & 13.89 & 8.67 & 6.33 & 7.30 & 0.67 & $<.0001$ & 0.221 & 0.262 \\
\hline Isovaleric (mmol/mol) & 3.07 & 3.75 & 2.08 & 1.85 & 2.39 & 0.18 & 0.002 & 0.055 & 0.144 \\
\hline Valeric (mmol/mol) & 1.23 & 1.33 & 0.94 & 0.92 & 1.07 & 0.06 & 0.018 & 0.210 & 0.226 \\
\hline $\mathrm{A} / \mathrm{P} *$ ratio & 3.22 & 3.37 & 3.02 & 2.73 & 3.24 & 0.12 & 0.023 & 0.945 & 0.434 \\
\hline Ammonia (mg/dL) & 21.82 & 5.95 & 5.94 & 3.02 & 4.20 & 1.72 & 0.006 & $<.0001$ & $<.0001$ \\
\hline $\mathrm{pH}$ & 6.91 & 6.95 & 7.05 & 6.95 & 7.07 & 0.06 & 0.270 & 0.968 & 0.326 \\
\hline \multicolumn{10}{|c|}{$\begin{array}{l}{ }^{1} \mathrm{CON}=\text { control (without natural additives); }{ }^{2} \mathrm{NA} 15-\text { addition of } 1.5 \mathrm{~g} / \text { animal/day of natural additives; }{ }^{3} \mathrm{NA} 30- \\
\text { addition of } 3.0 \mathrm{~g} / \text { animal/ day of natural additives; }{ }^{4} \mathrm{NA} 45-\text { addition of } 4.5 \mathrm{~g} / \text { animal/day of natural additives; }{ }^{5} \mathrm{NA} 60 \\
\text { - addition of } 6.0 \mathrm{~g} / \text { animal/day of natural additives. Naturals additives contained clove leaf essential oil, castor and } \\
\text { cashew functional oils and a commercial blend composed of vanillin, eugenol and thymol; }{ }^{6} \text { Standard error of means; } \\
{ }^{7} \text { Linear effect }{ }^{8} \text { Quadratic effect. * } \mathrm{A} / \mathrm{P}=\text { acetate/propionate ratio. }\end{array}$} \\
\hline
\end{tabular}

Table 4

Ruminal parameters of young bulls with and without natural additive addition to the diet

\section{Rumen bacterial diversity and abundance}

In our study, the major phyla present in the rumen were Bacteroidetes (47\%) and Firmicutes (36\%; Figure 1). Bacteroidetes $(P<0.05)$ were reduced when NA was included in the diet. A quadratic response was seen for Candidatus Saccharibacteria, Chytridiomycota, Elusimicrobia, Eukaryota Unassigned, Fibrobacteres, Firmicutes, Spirochaetes, Synergistetes and Tenericutes $(\mathrm{P}<0.05)$. Source data are included in supplementary material (Table S1).

The families Prevotellaceae (43\%) and Ruminococcaceae (20\%) were observed as the most abundant across treatments (Figure 2). Significant changes were observed in the families causing quadratic responses in Cardiobacteriaceae, 
Clostridiales_Family_XIII_Incertae_Sedis, Prevotellaceae, Ruminococcaceae. Our data also showed a decrease in Acidaminococcaceae, Coriobacteriaceae, Defluviitaleaceae, Desulfovibrionaceae, Neisseriaceae, Paenibacillaceae, Peptococcaceae, Porphyromonadaceae and an increase in Christensenellaceae, Bacillaceae, Lactobacillaceae, Ophryoscolecidae, Rikenellaceae, Trichomonadidae $(\mathrm{P}<0.05)$ post NA supplementation of bull diets. Source data are included in supplementary material (Table S2).

The most common rumen bacterial genera across the treatments were Succinivibrio, Succiniclasticum, Marvinbryantia and Prevotella (12\%, 11\%, 9\% and 6\%, respectively; Figure 3). A quadratic effect was observed when NA was supplemented into the bull diet with respect to the genera Alistipes, Asteroleplasma, Dorea, Elusimicrobium, Entodinium, Faecalibacterium, Haemophilus, Holdemanella, Paraprevotella, Pseudoscardovia, Pyramidobacter, Roseburia, Ruminobacter, Sphaerochaeta, Subdoligranulum, Syntrophococcus. A decrease in Acetitomaculum, Acidaminococcus, Akkermansia, Alloprevotella, Candidatus_Saccharimonas, Citreitalea, Clostridium, Fretibacterium, Mailhella, Moryella, Phascolarctobacterium, Prevotella, Robinsoniella, Succinimonas, Suttonella, Tetratrichomonas and Weissella and an increase in Anaerostipes, Atopobium, Bacillus, Bavariicoccus, Fibrobacter, Hydrogenoanaerobacterium, Paenibacillus and Sporobacter $(\mathrm{P}<0.05)$ was noted post NA dietary supplementation. Source data are included in supplementary material (Table S3).

\section{Methanogen diversity and abundance}

Archaeal abundance was reduced on the whole with the inclusion of NA in the bull diets $(P<0.05 ;$ Table 5$)$. The families Methanobacteriaceae and Methanomicrobiaceae $(P<0.05)$; orders Methanomicrobiales, Methanobacteriales and Methanomassiliicoccales $(P<0.05)$ and the genera Methanobrevibacter and Methanosphaera, showed a significant decrease with NA supplementation, whilst the genus Methanomicrobium showed a tendency to be present at lower abundance $(P=0.051)$. Furthermore, on a species level, a decrease in Methanobrevibacter ruminantium, Methanobrevibacter sp D5 and Methanobrevibactersp G16 was seen following NA supplementation of bull diets $(P<$ 0.05). 
Table 5

Archaea diversity and abundances from young bulls with and without natural additive addition to the diet

\begin{tabular}{|c|c|c|c|c|c|c|c|c|c|}
\hline \multirow[b]{2}{*}{ Archaea taxonomy } & \multicolumn{6}{|c|}{ Experimental diets } & \multicolumn{3}{|c|}{$P$ - value } \\
\hline & $\mathrm{CON}^{1}$ & NA15 ${ }^{2}$ & NA30 3 & NA45 ${ }^{4}$ & $N A 60^{5}$ & SEM & $\mathrm{L}^{7}$ & $\mathrm{Q}^{8}$ & $\begin{array}{l}0 \% v s \\
\text { blend }\end{array}$ \\
\hline Archaea Euryarchaeota & 2.00 & 2.22 & 2.08 & 1.74 & 1.93 & 0.422 & 0.434 & 0.847 & 0.977 \\
\hline f_Methanobacteriaceae & 88.53 & 17.29 & 19.61 & 18.40 & 14.56 & 13.800 & 0.956 & 0.918 & $<.0001$ \\
\hline f_Methanomicrobiaceae & 0.27 & 0.02 & 0.03 & 0.00 & 0.06 & 0.060 & 0.826 & 0.739 & 0.002 \\
\hline o_Methanomicrobiales & 21.89 & 2.74 & 5.77 & 4.09 & 3.94 & 4.794 & 0.844 & 0.692 & 0.005 \\
\hline o_Methanobacteriales & 19.84 & 2.90 & 3.34 & 3.87 & 2.48 & 3.442 & 0.845 & 0.991 & $<.0001$ \\
\hline o_Methanomassiliicoccales & 1.66 & 0.13 & 0.27 & 0.02 & 0.17 & 0.207 & 0.728 & 0.440 & $<.0001$ \\
\hline g_Methanobrevibacter & 211.22 & 42.48 & 36.31 & 40.08 & 43.89 & 14.733 & 0.909 & 0.786 & $<.0001$ \\
\hline g_Methanomicrobium & 0.74 & 0.04 & 0.23 & 0.05 & 0.18 & 0.264 & 0.981 & 0.557 & 0.051 \\
\hline g_Methanosphaera & 7.56 & 2.12 & 1.97 & 1.83 & 2.63 & 1.255 & 0.869 & 0.995 & $<.0001$ \\
\hline $\begin{array}{l}\text { S_Methanobrevibacter } \\
\text { ruminantium }\end{array}$ & 0.72 & 0.04 & 0.43 & 0.20 & 0.21 & 0.118 & 0.336 & 0.044 & 0.001 \\
\hline $\begin{array}{l}\text { S_Methanobrevibacter sp } \\
\text { D5 }\end{array}$ & 0.98 & 0.40 & 0.24 & 0.12 & 0.26 & 0.139 & 0.162 & 0.936 & $<.0001$ \\
\hline $\begin{array}{l}\text { s_Methanobrevibacter sp } \\
\text { G16 }\end{array}$ & 0.74 & 0.05 & 0.13 & 0.04 & 0.11 & 0.262 & 0.983 & 0.791 & 0.039 \\
\hline \multicolumn{10}{|c|}{$\begin{array}{l}{ }^{1} \mathrm{CON}=\text { control (without natural additives); }{ }^{2} \mathrm{NA} 15 \text { - addition of } 1.5 \mathrm{~g} / \text { animal/day of natural additives; }{ }^{3} \mathrm{NA} 30- \\
\text { addition of } 3.0 \mathrm{~g} / \text { animal/ day of natural additives; }{ }^{4} \mathrm{NA} 45 \text { - addition of } 4.5 \mathrm{~g} / \text { animal/day of natural additives; }{ }^{5} \mathrm{NA} 60 \\
\text { - addition of } 6.0 \mathrm{~g} / \text { animal/day of natural additives. Naturals additives contained clove leaf essential oil, castor and } \\
\text { cashew functional oils and a commercial blend composed of vanillin, eugenol and thymol; }{ }^{6} \text { Standard error of means; } \\
{ }^{7} \text { Linear effect; }{ }^{8} \text { Quadratic effect; } \mathrm{f}_{-}=\text {family taxonomy, g_ genus taxonomy; o_ = order taxonomy; s_= species } \\
\text { taxonomy. }\end{array}$} \\
\hline
\end{tabular}

\section{Gene Network correlations}

We observed close to 13,000 functionally annotated genes in total across the experimental samples using shotgun metagenomics and 28 were significantly differentially abundant when the bull diet contained NA (Fig. 4; Table S4). Functional annotation data showed significantly biological responses due to the NA addition whereas mostly related to protection against foreign attack to DNA and DNA maintenance, replication and repair (Restriction endonuclease, type II, Xaml; Restriction endonuclease, type II, EcoRV; Host-nuclease inhibitor protein Gam; RecG, N-terminal antiparallel four helix bundle; Type IV secretion system protein TraG/VirD4; Type IV secretion system, VirB10 / TraB / TrbI and Transposase, ISC1217). There were also functional process associated with membrane protection and maintenance (ABC-2 transporter; Conjugal transfer, TrbG/VirB9/CagX and Capsule biosynthesis protein CapC), metabolic role (Lyase, catalytic; Acyl-protein synthetase, LuxE; Phenolic acid decarboxylase, bacterial; Peptidase G2, IMC autoproteolytic cleavage domain; Glycyl radical enzyme, HI0521, predicted; Transposase, ISC1217 and Tetrahydrodipicolinate-Nsuccinyltransferase, chain A, domain 1), oxidative stress response (Thiol peroxidase conserved site and Aldehyde oxidase/xanthine dehydrogenase, molybdopterin binding), attack protection and resistance (Bacterial virulence protein VirB8; KorB, C-terminal and Siphovirus Gp157), plasmid replication (KorB, C-terminal), and unknown biologic process 
(Protein of unknown function DUF4244; Protein of unknown function DUF4054; Protein of unknown function DUF4912; Protein of unknown function DUF4294; Protein of unknown function DUF4416; Protein of unknown function DUF3853).

Specifically, the functional annotations Restriction endonuclease, type II, Xaml; Lyase, catalytic; Acyl-protein synthetase, LuxE; Host-nuclease inhibitor protein Gam; ABC-2 transporter; Transposase, ISC1217; RecG, N-terminal antiparallel four helix bundle and Protein of unknown function DUF4294 were decreased with NA inclusion in the diet. Furthermore, the annotations that showed an increase post NA inclusion in the diet were: Glycyl radical enzyme, HI0521, predicted; Aldehyde oxidase/xanthine dehydrogenase, molybdopterin binding, Peptidase G2, IMC autoproteolytic cleavage domain; Siphovirus Gp157; Type IV secretion system protein TraG/VirD4; Type IV secretion system, VirB10 / TraB / Trbl; Conjugal transfer, TrbG/VirB9/CagX; KorB, C-terminal and Protein of unknown function DUF4416. Nevertheless, a quadratic response was also noted for: Bacterial virulence protein VirB8; Capsule biosynthesis protein CapC; Phenolic acid decarboxylase, bacterial; Restriction endonuclease, type II, EcoRV; Thiol peroxidase conserved site; Tetrahydrodipicolinate-N-succinyltransferase, chain A, domain 1; Protein of unknown function DUF3853 and Protein of unknown function DUF4912.

The family Succinivibrionaceae had a strong positive correlation (average $r=>0.9$ ) with Tetrahydrodipicolinate-Nsuccinyltransferase, chain A, domain 1; Type IV secretion system, VirB10 / TraB / Trbl; Phenolic acid decarboxylase, bacterial; Thiol peroxidase conserved site; Type IV secretion system, VirB10 / TraB / Trbl; Bacterial virulence protein VirB8; Conjugal transfer, TrbG/VirB9/CagX; KorB, C-terminal gene abundances. The Paenibacillaceae bacterial family (Phylum Firmicutes) had a positive correlation ( $r=>0.9)$ with Peptidase $\mathrm{G} 2$ and Glycyl radical enzyme, HI0521, predicted gene abundance. The Victivallaceae interacted with Protein Function DUF4416 and Capsule Biosynthesis Protein CapC ( $r=>$ 0.9). The Glycyl radical enzyme, HI0521, predicted, showed a major correlation with Bacillaceae $(r=>0.9)$. Prevotellaceae had a negative correlation ( $r=-0.8$ ) with Ruminococcaceae, and Methanobacteriaceae also had a negative correlation ( $r$ $=>-0.7)$ with Protein Function DUF4294 and ABC-2 transporter gene abundances. Source data are included in supplementary material (Table S4, Fig. 6).

\section{Discussion}

In this study we evaluated the mechanism of action of a commercially available blend of essential oil, at increasing concentrations, on the rumen microbiome and host phenotype. Feeding behavior of ruminants is dependent on diet and the environment [21], and as expected, no differences were observed between treatments in this study. On average, animals spent 336 minutes at the feeder, 236 minutes ruminating, 35 minutes drinking water and the remaining at rest. Beef cattle tend to spend an average of 400 minutes eating and 300 ruminating when finished in feedlot [21]. Fiber content is a known factor influencing time spent ruminating and consequently in water ingestion due to the stimulus on the salivary glands [22]. The observed values in this study provide evidence of a healthy rumen, which is supported by the $\mathrm{pH}$ values, which are higher than 6.90 for all treatments. Ornaghi et al. [20], also observed similar feeding behavior when young bulls were fed diets with essential oils and 70:30 concentrate to roughage ratio. Moreover, Zotti et al. [23], fed monensin (included at $30 \mathrm{mg} / \mathrm{kg}$ or $40 \mathrm{mg} / \mathrm{kg}$ ) and functional oils (blend of castor oil and cashew nut shell liquid included at $400 \mathrm{mg} / \mathrm{kg}$ ) to a high concentrate diet (92.25\% concentrate) with 12 steers and observed no effects on feeding behavior parameters.

Essential oils are volatile and odorant compounds which can impact the palatability of the diet, positively or negatively [13], nonetheless we found no effects on DMI in this study. Our results are in agreement with those from Valero et al. [8], whereby bulls fed with $3 \mathrm{~g} /$ animal/day of ricinoleic acid (extracted from castor oil seed), anacardic acid, cardanol and cardol (extracted from the cashew nut shell liquid) during finishing had similar DMI (kg/day). On other hand, Yang et al. [24] reported an increase in DMI when cinnamaldehyde $(0.4,0.8$ and $1.6 \mathrm{~g} /$ day per animal) was fed to feedlot cattle 
during 28 days of observation. These variations might be related to the differing effects of the essential oils in isolation as opposed to presence in a mixture.

Secondary metabolites extracted from plants often have antimicrobial properties $[25,26]$. In our study, the main compounds present in the blend were: eugenol, vanillin, thymol, cardol, cardanol, ricinoleic acid, which can modulate the rumen fermentation and reduce methanogens abundance [27]. These compounds may improve the animal performance by modulating rumen fermentation $[8,10,20]$. Indeed, the ADG and feed efficiency increase linearly when NA were added to the diets. Furthermore, acetate, butyrate, isovaleric, valeric, and ammonia concentration were reduced when NA were added to the diets. Ornaghi et al. [20], also reported a significant increase in ADG using NA (clove essential oil and cinnamon essential oil in two different doses 3.5 and $7.0 \mathrm{~g} /$ animal/day) in the diet of young bulls finished in feedlot. However, most studies using NA are in vitro, and in vivo experiments are still scarce in literature. VFAs provide energy for the ruminant maintenance and to produce milk and meat. Nearly $252 \mathrm{kcal}$ are necessary to produce 1 mol of acetate, compared to $62 \mathrm{kcal}$ net gain to produce propionate [28], which also release free hydrogens used to produce methane by archaea (methanogens). We observed a reduction of Acetitomaculum, an important acetogenic bacterial genus, which utilizes monosaccharides to produce acetate, and is often found when cattle are fed high grain diets [29]. We also observed a reduction of the Acidaminococcus genus, which have acetate as major end-product [30]. Reducing the production of acetate can be positive to reduce environmental impact of beef cattle production as more energy is available to the animal as opposed to being lost in the form of methane.

Methanogens are commonly found in association with protozoa [31], which use hydrogenosomes to produce methane. In this study, the use of NA linearly reduced acetate and the archaeal population, that likely reduced methane production suggested by the reduction in archaea abundance. This decrease in the archaeal population post NA supplementation of diets could be due to hydrophobicity of phenolic compounds present in the NA, allowing permeation of the phospholipidic membrane resulting on cell lysis [32; 33]. Khorrami et al. [34] supplemented thyme and cinnamon essential oils ( $500 \mathrm{mg} / \mathrm{kg} \mathrm{DM}$ ) into ruminant diets and evaluated rumen fermentation and observed decreased protozoal and methanogens abundance, thus corroborating our data. Macheboeuf et al. [35], studied the production of methane in vitro following the inclusion of essential oils from five plants: Thymus vulgaris, Origanum vulgare, thymol chemo-type of O. vulgare, Cinnamomum verum, and Anethum graveolens); and three pure compounds: thymol, carvacrol, and cinnamaldehyde, and observed a decrease of methanogenesis up to $76 \%$ with the highest doses. Patra and Yu [6], also provided evidence for the inhibition of methanogenesis and decreases in protozoal density following addition of five essential oils from clove, eucalyptus, garlic, origanum and peppermint oils and using three different doses in vitro $(0.25$, 0.50 , and $1.0 \mathrm{~g} / \mathrm{L})$.

The effects of the NA blend on propionate production was quadratic and showed the maximum concentration at 4.5 level of natural mix addition. Propionate is the principal precursor of liquid glucose and is related to gluconeogenesis. In addition, production of propionate causes a net gain of around $62 \mathrm{kcal}$ of energy, therefore propionate is beneficial for ruminant production. There was a linear decrease of butyrate following the supplementation of NA to the diet of bull diets. Butyrate can inhibit propionate absorption, therefore is not as beneficial as an energy source for the ruminant [36]. Watanabe et al. [37], observed reduction of butyrate, acetate and methane production when raw cashew nut shell liquid was added to in vitro cultures. It is therefore important to highlight the dose-type dependent effect of the natural additives, which are enhanced when administered as a blend.

NA had a quadratic effect on ruminal ammonia concentration and was higher in bulls fed the control diet compared with those fed NA (21.82 vs $4.78 \mathrm{mg} / \mathrm{dL}$ ). This lower production may be related to the reduction in hyper-ammonia bacterial abundances, for example the Clostridium genus abundance was significant lower compared to the control diet. The Clostridium genus is one of the major ammonia producers and is highly affected by NA [39]. Furthermore, the genus Acidaminococcus and Robinsoniella were linearly reduced. The genus Acidaminococcus produces ammonia as the

Page $10 / 22$ 
major end product through glutamate fermentation [30]. The genus Robinsoniella is correlated with high ruminal ammonia concentration and with methanogens, which is due to a reflection of metabolic interaction among microbial consortium [40]. Thus, abundance decreases for both genera could impact the microbial consortium leading to lower methane production. Furthermore, the potential antimicrobial power of NA can be potentiated when the ruminal pH is low as in the grain diets such as in this study [39]. Furthermore, this decrease likely increases absorption of amino acids that are not broken to ammonia, which will be available for absorption in the gut [35]. In contrast, Jesus et al. [41], observed no significant effect on ruminal ammonia but an increase in propionate and lower blood urea concentration, suggesting a potential rumen fermentation shift, when a commercial blend (cashew nut shell liquid and castor oil) was fed to dairy cattle, these responses might be related to the animal basal diet. Recently, Cobellis et al. [17], reported that some essential oils can affect VFA production in the rumen but that it is dose and compound dependent, thus, they have specific effects on the rumen microbiome. As the rumen microbiome present a higher variability, some biological role can interact with the results of this study such as animal effect.

In terms of gene network interactions and function of the rumen microbiome, we found that Glycyl Radical and Peptidase function, were positively correlated to each other. The Ruminococcaceae family undergo changes with the inclusion of NA and had a positivel correlation with the abundance of protein Glycyl Radical genes, which are found to contribute to environmental resilience, and are also potentially related with VFA production [42]. The abundance of Prevotellaceae was negatively correlated with Ruminococcaceae; the two major bacterial families found in our study. Both families are known to compete for the same niche in the rumen [43] perhaps explaining their negative correlations to each other. Blautia tended to increase linearly, even in a low concentration. This taxon can improve polysaccharides utilisation, improving the rumen fermentation [44]. Some Blautia species can consume $\mathrm{H}_{2}$ increasing the acetogenesis, which can lead to competition with the methanogens [45]. Nonetheless, the Peptococcaceae family was reduced using the blend of NA. This family is a producer of $\mathrm{H}_{2}$ from amino acids or carbohydrates fermentation. The impact on Blautia genus and Peptococcaceae family might be a secondary cause of the methanogens reduction as the competition for substrates and $\mathrm{H}_{2}$ lower production can reduce the archaea abundance [46].

There is no doubt that the rumen is a complex environment [47]. Understanding the abundance of the microbes is and their function is nonetheless crucial when investigating the mechanisms of action of a novel additive and to ensure no detrimental effects are encountered. In this study, we show that the essential oil blend used affected the rumen microbiome, potentially through disruption of bacterial cell membranes and breakdown in DNA replication $[17,18,26$, 38]. Important bacterial defense mechanisms used by microbes were observed in our study, such as DNA replication and protection against attack from outsider metabolites, being mostly from membrane sites in response to encountering the blend of essential oils. Furthermore, one of the major protein annotations in our study was the ABC transporter group, the key role of this protein is translocating molecules across the membrane to the maintenance of the cell, followed by multidrug or antimicrobial efflux pumps [30]. This protein was affected and decreased by NA addition. [30]. We also noted some DNA restrictions modification mechanisms used for protection of bacterial and archaea against invading foreign DNA were reduced by NA addition, both Restriction endonuclease, type II Xaml and EcoRV, to date the difference between them are in the mode of recognition process and cleavage [48].

\section{Conclusions}

In our study, the blend of natural additives improved animal performance by beneficial modulating the rumen microbiome. Furthermore, our data suggest that methane emissions may be decreased with NA levels from $3 \mathrm{~g} / \mathrm{animal} /$ day addition in this study, suggested by the archaeal reduction. Ammonia rconcentrations were also reduced which is also of major benefit for the environment. Also, we can conclude that the level $4.5 \mathrm{~g} / \mathrm{animal} / \mathrm{day}$ in this study had improved animal performance, thus, may replace the use of antibiotics in beef cattle finished in a feedlot with high

Page $11 / 22$ 
grain diets. These positive results are mainly a consequence of the ability of the NA blend to beneficially modulate the rumen microbiome.

\section{Materials And Methods}

\section{Animals and diets}

A total of 40 ( $1 \frac{1}{2}$ Angus vs $1 / 2$ Nellore) young bulls of $16 \pm 2.2$ months of age and with a body weight of $385.8 \pm 20.7 \mathrm{~kg}$ were used in this study. A 14-d adaptation period before starting the experiment was used, during which the concentrate was gradually increased for the animals. The bulls were weighed every 28 days at a trunk balance (Beckehauser Cia. Paranavaí city, Paraná, South Brazil).

Bulls were fed with a basal diet comprised of $70 \%$ concentrate and $30 \%$ corn silage offered ad libitum for 62 days (Table 1), and feed intake was recorded individually every day for $5 \%$ leftovers. Feed samples were collected every day, and stored at $-20^{\circ} \mathrm{C}$ prior to analysis. Bulls were randomized on five treatments: control (CON), without the addition of naturals additives; NA15, with the addition of $153.07 \mathrm{mg}$ per $\mathrm{kg}$ of DM of a blend of naturals additives ( $1.5 \mathrm{~g}$ /day/animal); NA30, $305.2 \mathrm{mg}$ per $\mathrm{kg}$ of DM of a blend of naturals additives (3.0 g/day/animal); NA45, $444.66 \mathrm{mg}$ per $\mathrm{kg}$ of DM of a blend of naturals additives (4.5 g/day/animal): NA60, addition of $594.65 \mathrm{mg}$ per $\mathrm{kg}$ of DM of a blend of naturals additives $\left(6.0 \mathrm{~g} /\right.$ day/animal). The blend of natural additives contained clove leaf essential oil (Ferquima ${ }^{\circledR}$, Vargem Grande Paulista, São Paulo, Brazil), castor and cashew functional oils (Safeeds®, Cascavel, Paraná, Brazil) and a commercial blend composed of vanillin, eugenol and thymol (Safeeds ${ }^{\circledR}$, Cascavel, Paraná, Brazil).

Following day 62 in the feedlot, the animals were weighed after 16 hours of fasting $(482 \pm 31.9 \mathrm{~kg})$ and transported to a commercial slaughterhouse (Campo Mourão city, Paraná, South Brazil). The truck stocking density was $0.8 \pm 0.2$ bulls $/ \mathrm{m}^{2}$, and the transport distance was less than $90 \mathrm{~km}$. The bulls were slaughtered following the usual practices of the Brazilian beef industry. The animals were stunned using a captive-bolt pistol. Then, they were bled through exsanguinations by cutting the neck vessels, and the head hide, viscera, tail, legs, diaphragm and excess internal fat were removed. Afterwards, the carcasses were divided medially from the sternum and spine, resulting in two similar halves, which were weighed to calculate the hot carcass weight $(\mathrm{HCW})$. Then, the half-carcasses were washed, weighed, identified and stored in a chilling chamber at $4{ }^{\circ} \mathrm{C}$, where they remained for a $24 \mathrm{~h}$ period and drip loss measured by the difference between the hot carcass weight and the carcass weight observed 24 hours later after chilling. The hot carcass dressing (HCD) percentage was defined as the hot carcass weight divided by the FBW 16 hours before slaughter and calculated by using the equation: $\mathrm{HCD}=(\mathrm{HCW} / \mathrm{FBW}) \times 100$.

\section{Diet chemical analyses}

The dry matter (DM) content of the ingredients was determined by oven-drying at $65^{\circ} \mathrm{C}$ for $24 \mathrm{~h}$ and then drying at $135^{\circ} \mathrm{C}$ for $3 \mathrm{~h}$ (Method 930.15) [49]. The organic matter (OM) content was calculated as the difference between the DM and ash contents, with ash determined by combustion at $550{ }^{\circ} \mathrm{C}$ for $5 \mathrm{~h}$ [49]. The $\mathrm{N}$ content in the samples was determined by the Kjeldahl method (Method 976.05) [49]. The neutral detergent fibre (NDF) and acid detergent fibre (ADF) contents were determined using the methods described by Van Soest et al. [21], using heat stable a-amylase and sodium sulphite for the NDF procedure, and residual ash. The factor of 0.82 was used to convert metabolizable energy requirement to digestible energy requirements, and the factor 4.1868 was used to convert total digestible nutrients requirement to megajoules (NRC, 2000).

\section{Feeding behavior}


In order to evaluate diet effects on feeding behavior, the young bulls were subjected to two periods of $24 \mathrm{~h}$ of observation using five-minute intervals and three trained evaluators. A total of 288 observations were performed for each animal. Animals were adapted to feeding behavior evaluation for five days prior to the start of evaluations. Water and feed intake, and rumination and idle periods were obtained by the sum of 288 observations (minute/day). Observations were performed without interfering with the animal's routine. The water intake was considered when animals were at the individual water reservoir, and feed intake was considered when animals were at the feeder. Rumination was considered when animals were chewing a bolus. Idle was considered when animals were not performing any of the activities described previously [50].

\section{Rumen sampling}

Fresh rumen content was collected at the end of the experimental period ( 5 days before the slaughter) $4 \mathrm{~h}$ before animals were fed, from 25 animals chosen at random ( 5 on each treatment). Rumen contents were sampled by a trained veterinarian using an esophageal probe and vacuum pump. Rumen liquor $(50 \mathrm{~mL})$ were sampled from the ventral region of the rumen and was then strained through two layers of muslin. The $\mathrm{pH}$ was recorded immediately using a $\mathrm{pH}$ meter (Hanna instruments model HI99163, Romaria - Brazil); the electrode was previously calibrated and then inserted into the rumen fluid. Sub-samples used to evaluate volatile fatty acids (VFA) and ammonia concentrations were preserved by the addition of trichloroacetic acid (25\%; v/v) following storage in ultra-freezer $\left(-80^{\circ} \mathrm{C}\right)$. Sub-samples used to evaluate protozoal count were preserved using formaldehyde (4\%; v/v/).

\section{Ruminal ammonia and VFA measurements}

Ruminal ammonia-N concentration was determined using the distillation method (Kjeltec Auto 1030 Analyzer Tecator, Hoganas, weden). Ruminal fluid samples were analyzed for VFA by gas chromatography (Shimadzu, Model GC-2014, automatic injection model AOC - 20i) equipped with a 30-m (0.32 mm ID) silica-fused column (HP INNOwax - 19091N Capillary Column, Varian, Palo Alto, CA, USA). Helium and crotonic acid (trans-2-butenoic acid) were used as carrier gas and internal standard, respectively. Oven initial and final temperatures were 55 and $195^{\circ} \mathrm{C}$, respectively, and detector and injector temperatures were adjusted at $250^{\circ} \mathrm{C}$.

\section{DNA extraction, Metagenomic Library Preparation and Sequencing}

DNA was extracted from the rumen liquid after thawing samples at $4{ }^{\circ} \mathrm{C}$ using a FastDNA SPIN Kit for Soil (MP Biomedicals, Irvine, CA, USA) according to manufacturer's guidelines. The integrity of the DNA was verified using agarose gel electrophoresis. DNA was quantified using Pico 100 (Picodrop, Ltd., Hinxton, UK). Extracted genomic DNA were normalized to $10 \mathrm{ng} / \mu \mathrm{L}$ with PCR grade water (Roche Diagnostics Limited, Mannheim, Germany) and 50 ng were used to prepare metagenomic libraries using the Nextera ${ }^{\circledR}$ DNA kit (Illumina, San Diego, United States) following standard instructions. Nextera ${ }^{\circledR}$ DNA libraries were quantified. Sample libraries were pooled in equimolar concentrations following Illumina guidelines and sequenced at $2 \times 151$ bp using an Illumina HiSeq 2500 rapid run, with samples duplicated over two lanes, and following standard manufacturer's instructions. Sequence data quality control and analyses were performed using the QIIME pipeline, version 1.7.0 [51]. Illumina adapters and primers were removed, and the forward and reverse reads were paired.

\section{Rumen microbiome diversity, function and gene network correlations}


Taxonomic and functional analysis data were assessed with MGnify (http://www.ebi.ac.uk/metagenomics) following the pipeline version 5.0. Differential abundances of gene functional categories were assessed between dietary treatments using DESeq2 [52]. The input for correlation analysis was performed with the normalized counts taken over all samples from the internal normalization calculated by DESeq2. We applied a P-value cut-off of 0.01 to the resulting domain predictions and counted the number of gene functional which were assigned domains using volcano plots to the differences between control diet and the treatments. Correlations between datasets (biological taxonomy and functional annotation) were calculated using Pearson's rank correlation using R software and visualized with ggplot package. The differences were considered significant at Bonferroni corrected $p$-value $<0.05$. After the correlation procedure and $p$ adjusted values the results were used to develop the functional annotation of proteins and biological taxonomy network using standard procedures of the software Cytoscape.

\section{Statistical analyses}

In the current study, only microbial taxa with a relative abundance higher than 10 reads were considered and used for the analysis. Bacterial abundance profiles were summarized at phyla, family and genus levels, and archaeal communities were summarized to species level. Relative abundances of microbial taxa were normalized to the lowest reads number for bacteria, and then compared among diet using analysis of variance (ANOVA) and the MIXED procedure to determine the linear and quadratic effects and assess the effects of the treatment control versus blend of NA. All performance data were tested for normality and showed a normal distribution. The data were analyzed using ANOVA and by use of regression equations using the MIXED procedure. In all statistical analyses, the diet was considered a fixed effect, and the animals considered a random effect. Treatment means were computed with the LSMEANS option.

$Y i j=\beta 0+\beta_{1} X_{i}+\beta_{2} X_{i}^{2}+\varepsilon i j$

where:

Yij observation of the repetition $\mathrm{j}$ on treatment $\mathrm{i}$;

$\beta 0$ general coefficient;

$\beta 1$ linear regression coefficient of the variable observed depending on the levels;

$\beta 2$ quadratic regression coefficient of the variable observed depending on the levels;

Xi independent variables (blend of NA levels);

Eij residual error.

The statistical analyzes were performed using SAS (2004) (Institute Inc., Cary, NC) for Windows and R package. In addition, the stacked bar was built in Microsoft Excel, version 16.

\section{Abbreviations}

ADF: acid detergent fibre

ANOVA: Analysis of variance

bp: base pairs

CON: Control 
DM: Dry matter

DNA: Deoxyribonucleic acid

FBW: Final body weight

HCD: Hot carcass dressing

HCW: Hot carcass weight

NA: Natural additives

NDF: neutral detergent fibre

OM: Organic matter

pH: Potential hydrogenation

VFA: Volatile fatty acid

\section{Declarations}

\section{Availability of data and materials}

The raw FASTA files of the sequence data were submitted to European Bioinformatics Institute (EMBL-EBI) Sequence Read Archive database with accession number ERP112000 (https://www.ebi.ac.uk/metagenomics).

\section{Funding}

The current project was funded by Coordination for the Improvement of Higher Education Personnel (CAPES) and the Brazilian Council for Research and Technological Development (CNPq). SAH is also in receipt of an RCUK Newton Institutional Link Funding (172629373), BBSRC GCRF grant (BB/S014748/1) MGO obtained CNPq funding to complete the sandwich year of her PhD with SAH (Finance Code 201675/2018-8).

\section{Acknowledgements}

SAH acknowledges receipt of a CNPq special visiting fellowship award at Universidade Estadual de Maringá. The authors thank the Safeeds Nutrição Animal (Cascavel, Paraná State, Brazil South). The trade names or commercial products in this publication are mentioned solely for the purpose of providing specific information and do not imply recommendations or endorsement by the Department of Animal Science, Universidade Estadual de Maringá.

\section{Contributions}

Designed the experiment: MO, IP; Field work conduction: MO, TR; Rumen fluid collection: MO, CM, TR, FC; Laboratory procedures: MO, RP; Generation and analysis of the microbiome data: MO, SH, CC. Wrote the manuscript: MO, RP, SH, CC, IP. All authors read and approved the final manuscript.

\section{Consent for publication}




\section{Ethics declaration}

All animal care and experimental procedures were conducted under the surveillance of the Animal Care and Use Committee of the Universidade Estadual de Maringá, Brazil (approval No 8583060318) and met the guidelines of the National Council for the Control of Animal Experimentation (CONCEA).

\section{Declaration of interest}

The authors declare no conflicts of interest.

\section{References}

1. Ramírez-Restrepo CA, Tan C, O’Neill CJ, López-Villalobos N, Padmanabha J, Wang J and McSweeney CS. Methane production, fermentation characteristics, and microbial profiles in the rumen of tropical cattle fed tea seed saponin supplementation. Anim Feed Sci and Technol, 2016;216, 58:67.

2. Tapio I, Snelling TJ, Strozzi F and Wallace RJ. The ruminal microbiome associated with methane emissions from ruminant livestock. J Anim Sci Biotechnol. 2017;8, 7.

3. Russell JB and Houlihan AJ. lonophore resistance of ruminal bacteria and its potential impact on human health. FEMS Microbiol Rev, 2003;27, 65-74.

4. Hitch TC, Thomas BJ, Friedersdorff JC, Ougham H, Creevey CJ. Deep sequence analysis reveals the ovine rumen as a reservoir of antibiotic resistance genes. Environ Pollut. 2018;1,235:571-5.

5. Chaves, AV, He M. L Yang, W Z, Hristov A N., McAllister T A, Benchaar C. Effects of essential oils on proteolytic, deaminative and methanogenic activities of mixed ruminal bacteria. Can J Anim Sci. 2008;88:117-122.

6. Patra AK, Yu Z. Effects of essential oils on methane production and fermentation by, and abundance and diversity of, rumen microbial populations. Appl Environ Microbiol. 2012;78,4271-4280.

7. Jayasena DD and Jo C. Essential oils as potential antimicrobial agents in meat and meat products: A review. Trends Food Sci Technol. 2013;34,96-108.

8. Valero MV, Prado RM, Zawadzki F, Eiras CE, Madrona GS and Prado IN. Propolis and essential oils additives in the diets improved animal performance and feed efficiency of bulls finished in feedlot. Acta Sci Anim Sci. 2014;36,419426.

9. Fugita CA, Prado RM, Valero MV, Bonafé EG, Carvalho CB, Guerrero A, Prado IN. Effect of the inclusion of natural additives on animal performance and meat quality of crossbred bulls (Angus $\times$ Nellore) finished in feedlot. Anim Prod Sci. 2018;58,2076-2083.

10. Geraci JI, Garciarena AD, Gagliostro GA, Beauchemin KA and Colombatto D. Plant extracts containing cinnamaldehyde, eugenol and capsicum oleoresin added to feedlot cattle diets: Ruminal environment, short term intake pattern and animal performance. Anim Feed Sci Technol. 2012;176,123-130.

11. Shah MA, Bosco SJD, Mir SA. Plant extracts as natural antioxidants in meat and meat products. Meat Science. 2014;98,21-33.

12. Feldberg RS, Chang SC, Kotik AN, Nadler M, Neuwirth Z, Sundstrom DC and Thompson NH. In vitro mechanism of inhibition of bacterial cell growth by allicin. Antimicrob Agents Chemother. 1988;32,1763-1768. 
13. Franz C, Baser KHC, Windisch W. Essential oils and aromatic plants in animal feeding - a European perspective. A review. Flavour Fragr J. 2010;25,327-340.

14. Radünz M, Trindade MLM, Camargo TM, Radünz AL, Borges CD., Gandra EA, Helbig E. Antimicrobial and antioxidant activity of unencapsulated and encapsulated clove (Syzygium aromaticum, L.) essential oil. Food Chem. 2019;276, 180-186.

15. Arshad MS, Batool SA. Natural Antimicrobials, their Sources and Food Safety. Food Additives. 2017;87.

16. Biondo PBF, Carbonera F, Zawadzki F, Chiavellia LUR, Pilau EJP, Prado IN, Visentainer JV. Antioxidant capacity and identification of bioactive compounds by GC-MS of essential oils commercialized in Brazil. Curr Bioact Compd. 2017;13, 137-143.

17. Cobellis G, Trabalza-Marinucci M, Marcotullio MC, Yu Z. Evaluation of different essential oils in modulating methane and ammonia production, rumen fermentation, and rumen bacteria in vitro. Anim Feed Sci Technol. 2016;215, 25-36.

18. Benchaar C, Greathead H. Essential oils and opportunities to mitigate enteric methane emissions from ruminants. Anim Feed Sci Technol. 2011;166-167, 338-355. https://doi.org/10.1016/j.anifeedsci.2011.04.024.

19. Bassolé IHN, Juliani HR. Essential oils in combination and their antimicrobial properties. Molecules. 2012;17,39894006.

20. Ornaghi MG, Passetti RAC, Torrecilhas JA, Mottin C, Vital ACP, Gurerrero A, Sañudo C, Campo MM and Prado IN. Essential oils in the diet of young bulls: Effect on animal performance, digestibility, temperament, feeding behaviour and carcass characteristics. Anim Feed Sci Technol. 2017;234, 274-283.

21. Van Soest PJ. Nutritional ecology of the ruminant. Cornell University Press, Ithaca. 1994, NY, USA.

22. Dulphy JP, Remond B, Theriez M. Ingestive behaviour and related activities in ruminants. Digestive Physiology and Metabolism In Ruminants (eds. Y Ruckebusch and P Thivend), Clermont Ferrand: Springer France; 1980. p. 103-122,

23. Zotti CA, Silva AP, Carvalho R, Marino CT, Rodrigues PHM, Silva LFP, McAllister TA, Leme PR. Monensin and a blend of castor oil and cashew nut shell liquid used in a high-concentrate diet abruptly fed to Nellore cattle. J Anim Sci. 2017;95,4124-4138.

24. Yang WZ, Ametaj BN, Benchaar C, He ML, Beauchemin KA. Cinnamaldehyde in feedlot cattle diets: Intake, growth performance, carcass characteristics, and blood metabolites. J Anim Sci. 2010;88,1082-1092.

25. Dorman HJD, Deans SG. Antimicrobial agents from plants: antibacterial activity of plant volatile oils. J Appl Microbiol. 2000;88,308-316.

26. Patra AK. Effects of essential oils on rumen fermentation, microbial ecology and ruminant production. Asian J Anim Vet Adv. 2011,6,416-428.

27. Newbold CJ, Williams AG and Chamberlain DG. The in-vitro metabolism of D, L-lactic acid by rumen microorganisms. J Sci Food Agric. 1987;38, 9-18.

28. Hungate RE. The Rumen and its Microbes Academic Press. 1966; New York.

29. Hua C, Tian J, Tian P, Cong R, Luo Y, Geng Y, Tao S, Ni Y, Zhao R. Feeding a high concentration diet induces unhealthy alterations in the composition and metabolism of ruminal microbiota and host response in a goat model. Front Microbiol. 2017;8,138.

30. Chang YJ, Pukall R, Saunders E, Lapidus A, Copeland A, Nolan M, Cheng JF. Complete genome sequence of Acidaminococcus fermentans type strain (VR4 T). Stand Genomic Sci. 2010;3,1.

31. Finlay BJ, Esteban G, Clarke KJ, Williams AG, Embley TM, Hirt RP. Some rumen ciliates have endosymbiotic methanogens. FEMS Microbiol Lett. 1994;117,157-161.

32. Hungate RE. The rumen and its microbes. Elsevier. 2013.

33. Williams AG, Coleman GS. The rumen protozoa. In The rumen microbial ecosystem (eds. PN Hobson and CS Stewart). Blackie Academic and Professional, Netherlands; 1994. p. 73-139

Page $17 / 22$ 
34. Khorrami B, Vakili AR, Mesgaran MD and Klevenhusen F. Thyme and cinnamon essential oils: Potential alternatives for monensin as a rumen modifier in beef production systems. Anim Feed Sci Technol. 2015;200,8-16.

35. Macheboeuf D, Morgavi DP, Papon Y, Mousset JL and Arturo-Schaan M. Dose-response effects of essential oils on in vitro fermentation activity of the rumen microbial population. Anim Feed Sci Technol. 2008;145,335-350.

36. Aiello RJ, Armentano LE, Bertics SJ, Murphy AT. Volatile fatty acid uptake and propionate metabolism in ruminant hepatocytes. J Dairy Sci. 1989;72, 942-949.

37. Watanabe Y, Suzuki R, Koike S, Nagashima K, Mochizuki M, Forster R, Kobayashi Y. In vitro evaluation of cashew nut shell liquid as a methane-inhibiting and propionate-enhancing agent for ruminants. Journal of Dairy Science. 2010;93,5258-5267.

38. Newbold CJ, Mclntosh FM, Williams P, Losa R and Wallace RJ. Effects of a specific blend of essential oil compounds on rumen fermentation. Anim Feed Sci Technol. 2004;114,105-112.

39. Wallace RJ, McEwan NR, McIntosh FM, Teferedegne B and Newbold CJ 2002. Natural products as manipulators of rumen fermentation. Asian Australasian Journal of Animal Sciences 15, 1458-1468.

40. Hernandez-Sanabria E, Goonewardene LA, Wang Z, Zhou M, Moore SS. Influence of sire breed on the interplay among rumen microbial populations inhabiting the rumen liquid of the progeny in beef cattle. PloS one. 2013;83:e58461.

41. Jesus EF, Del Valle TA, Calomeni GD, Silva TH, Takiya CS, Vendramini THA, Paiva PG, Silva GG, Netto AS and Renno FP. Influence of a blend of functional oils or monensin on nutrient intake and digestibility, ruminal fermentation and milk production of dairy cows. Anim Feed Sci Technol. 2016;219,59-67.

42. Backman LR, Funk MA, Dawson CD, Drennan CL. New tricks for the glycyl radical enzyme family. Crit Rev Biochem Mol Bio. 2017;52,674-695.

43. Kim M, Morrison M, Yu Z. Status of the phylogenetic diversity census of ruminal microbiomes. FEMS Microbiol Ecol. 2011;76:49-63.

44. Li F, Hitch TC, Chen Y, Creevey, CJ. Comparative metagenomic and metatranscriptomic analyses reveal the breed effect on the rumen microbiome and its associations with feed efficiency in beef cattle. Microbiome. 2019;7 6.

45. Rey FE, Faith JJ, Bain J, Muehlbauer MJ, Stevens RD, Newgard CB, Gordon JI. Dissecting the in vivo metabolic potential of two human gut acetogens. J Biol Chem. 2010;285:22082-90.

46. Kamra DN, Singh B. Rumen Microbiome and Plant Secondary Metabolites (PSM): Inhibition of Methanogenesis and Improving Nutrient Utilization. Advancing Frontiers in Mycology \& Mycotechnology. 2019;325-345. Springer, Singapore.

47. Huws SA, Creevey CJ, Oyama LB, Mizrahi I, Denman SE, Popova M, Tapio I. Addressing global ruminant agricultural challenges through understanding the rumen microbiome: Past, present, and future. Front Microbiol. 2018;9.

48. Pingoud A, Fuxreiter M, Pingoud V, Wende W. Type II restriction endonucleases: structure and mechanism. Cell Mol Life Sci. 2005;62,685.

49. Assotiation OOACA. Official methods of analysis of AOAC. 2005.

50. Silva RR, Silva FF, Prado IN, Carvalho GGP, Franco IL, Almeida ICC, Cardoso CP, Ribeiro MHS. Comportamento ingestivo de bovinos. Aspectos metodológicos. Arch Zootec. 2006;55,293-296.

51. Caporaso JG, Kuczynski J, Stombaugh J, Bittinger K, Bushman FD, Costello EK, Huttley GA. QIIME allows analysis of high-throughput community sequencing data. Nature methods. 2010;7,335.

52. Love MI, Huber W, Anders S. Moderated estimation of fold change and dispersion for RNA-seq data with DESeq2. Genome biology. 2014;15:550.

\section{Figures}

Page $18 / 22$ 


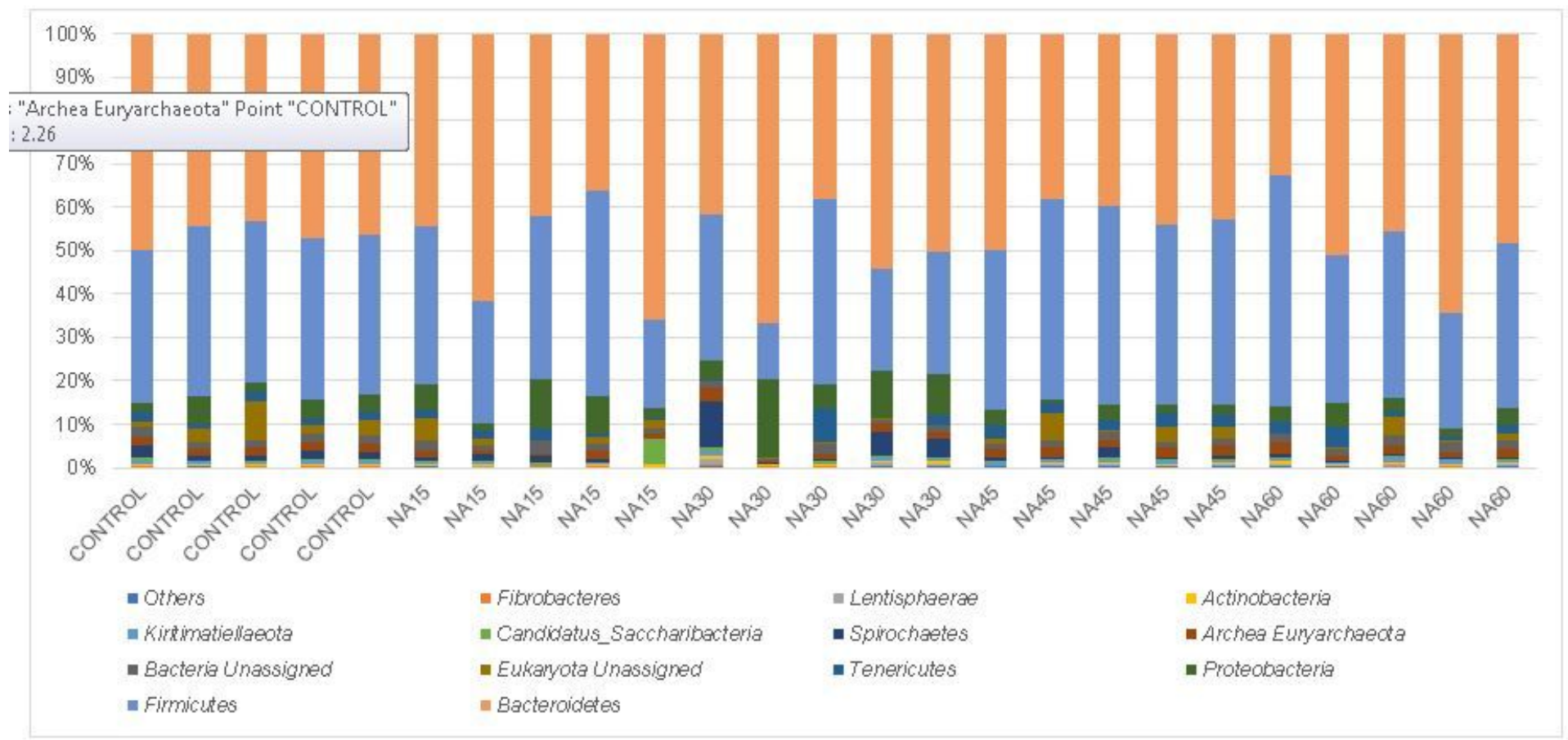

\section{Figure 1}

Relative abundance of rumen microbiota based on phyla level and taken from young bulls finished in a feedlot and fed with and without natural additives. Sequences that represented $<10 \%$ in a sample were combine in others (blue) to aid the visualization.

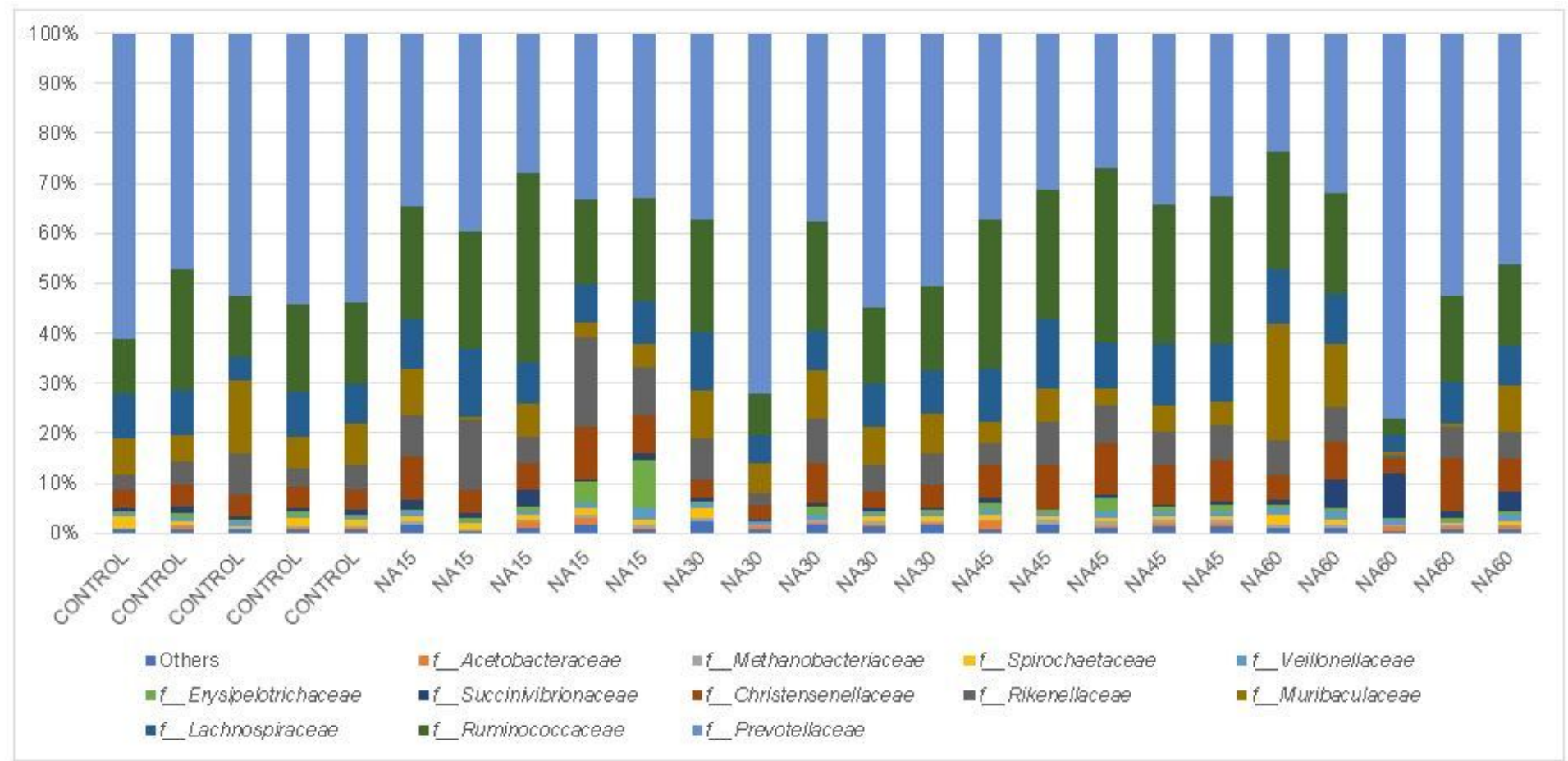

\section{Figure 2}

Relative abundance of rumen microbiota on family level of young bulls finished in feedlot and fed natural additives. Sequences that represented $<10 \%$ in a sample were combine in others (blue) to aid the visualization. 


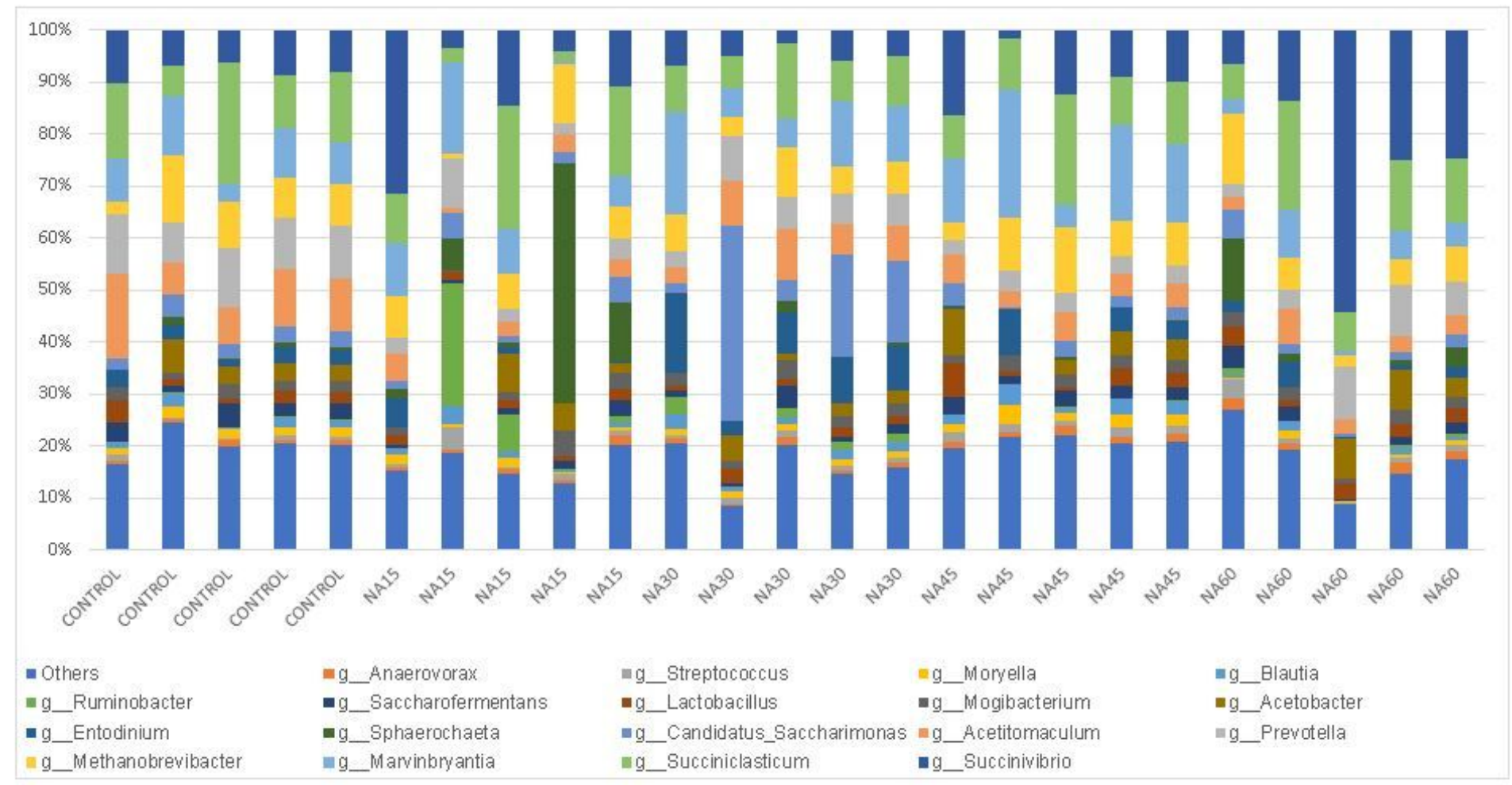

Figure 3

Relative abundance of rumen microbiota on a genera level and taken from young bulls finished in feedlot and fed with and without natural additives. Sequences that represented $<1.5 \%$ in a sample were combine in others (blue) to aid the visualization.

A. Con versus $\mathrm{Na15}$

- NS \& Log $2 F C$ \& P P 8 Log $2 F C$

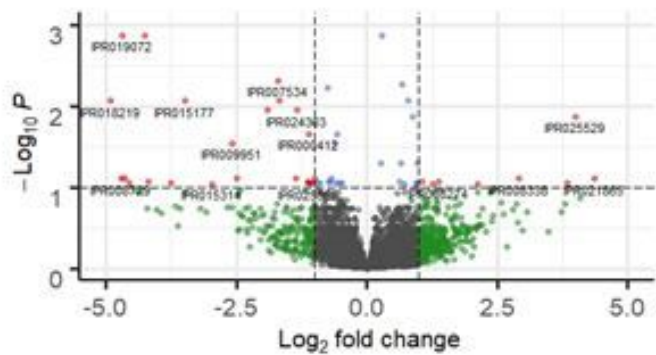

c.

Con versus $\mathrm{Na} 45$

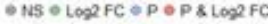

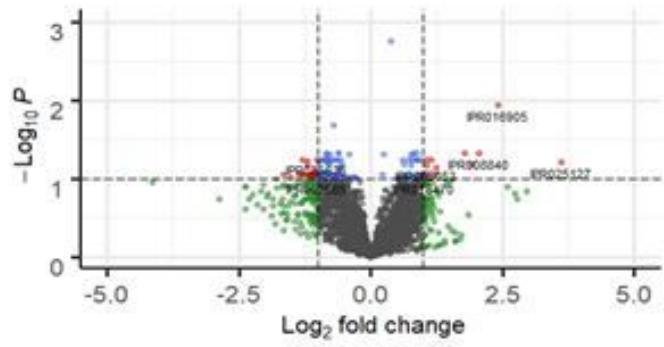

\section{B. Con versus $\mathrm{Na} 30$}

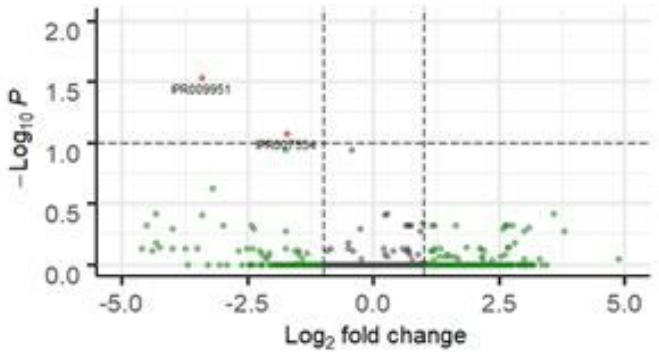

D.

Con versus Na60

- NS $\odot \log 2 \mathrm{FC}$ OP $O P \& \log 2 F C$

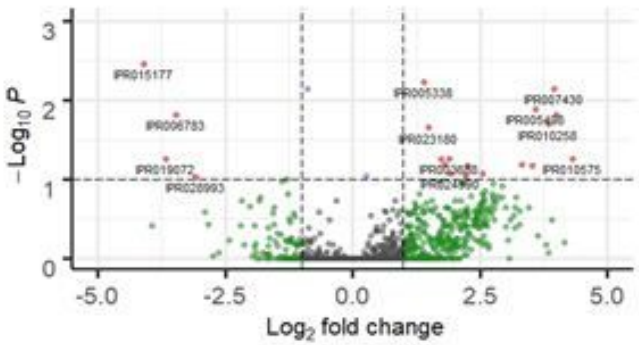

Figure 4 
Volcano plot of rumen microbial genes following shotgun metagenomic sequencing of samples obtained from young bulls finished in the feedlot and fed with and without natural additives. Black dots represent non-significantly differentially expressed proteins, green dots represent proteins significantly differentially expressed at pFDR $<0.05$ while red dots represent the most significantly differentially expressed proteins; A - Control diet versus Na15 (addition of 1.5 $\mathrm{g} /$ animal/day of natural additives), B - Control diet versus Na30 (addition of $3.0 \mathrm{~g} / \mathrm{animal} /$ day of natural additives), C Control diet versus Na45 (addition of $4.5 \mathrm{~g}$ /animal/day of natural additives), D - Control diet versus Na60 (addition of $6.0 \mathrm{~g} / \mathrm{animal} /$ day of natural additives).

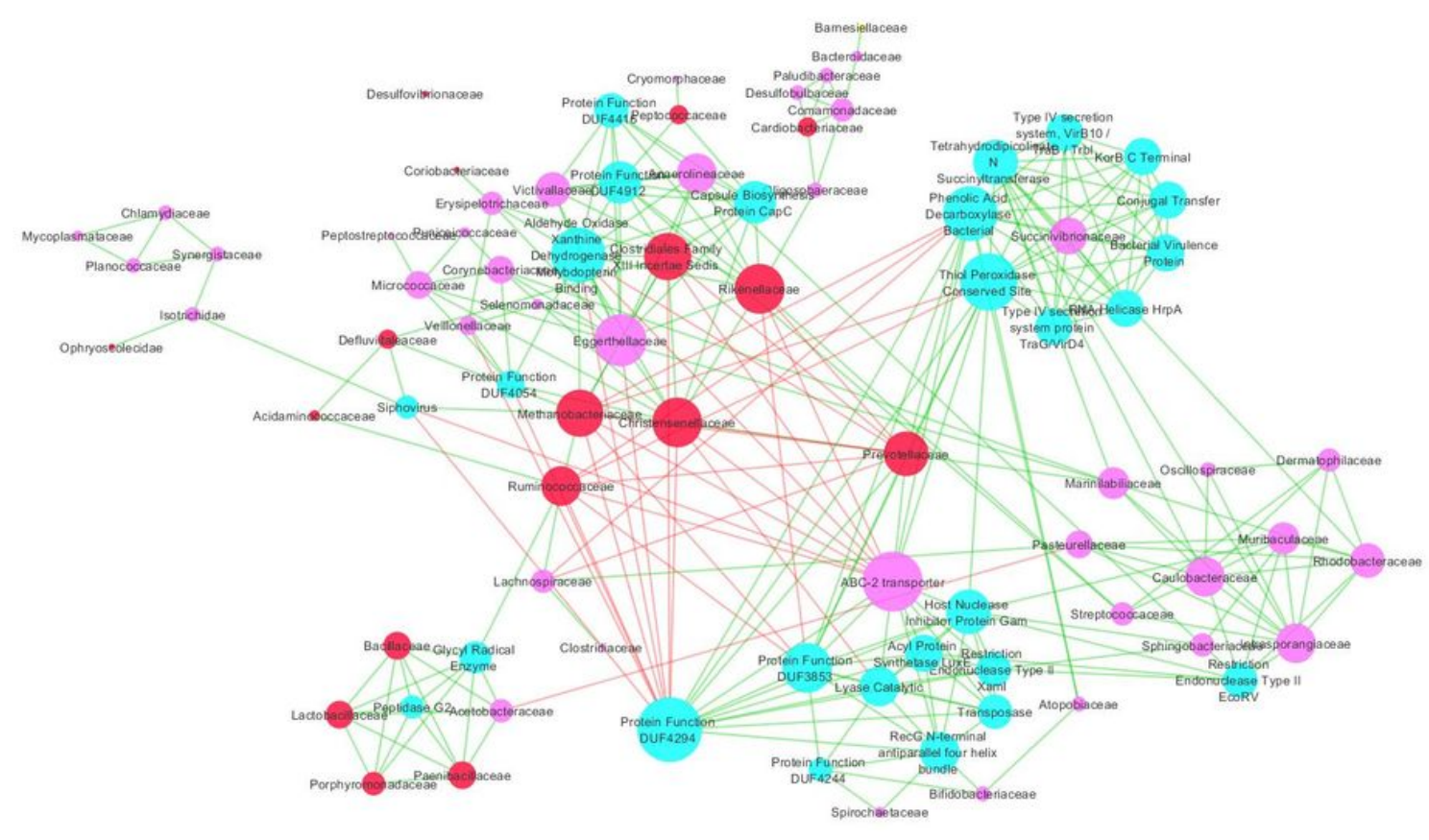

\section{Figure 5}

Gene network correlation between rumen diversity and gene functional annotation $\mathrm{P}<0.05$; light blue nodes) and biological taxonomy family abundance (pink nodes) of young bulls finished in feedlot and fed natural additives. The nodes size is related to the number of directed edges. Green lines are positive correlation $(r 2=>0.5)$ and red lines negative correlation $(r 2=<-0.5)$. Family taxonomy abundance with significant effect between treatments $(P<0.05$; red nodes) 


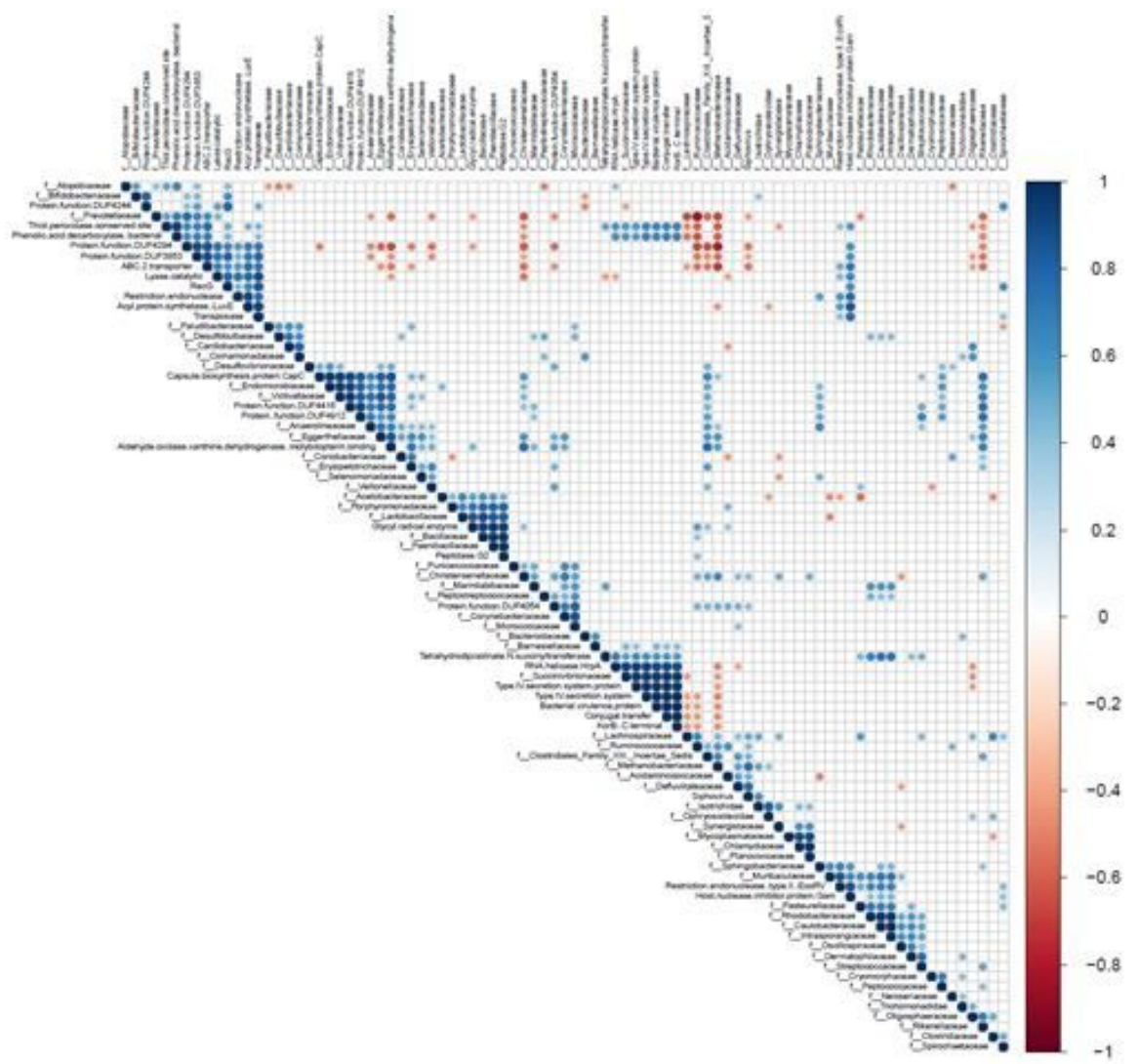

Figure 6

Correlogram between functional annotation of genes and biological taxonomy on a family levels from samples taken from young bulls finished in feedlot and fed with and without natural additives $(P<0.05)$.

\section{Supplementary Files}

This is a list of supplementary files associated with this preprint. Click to download.

- SupplementaryTable130520AnimalMicrobiome.docx 